\title{
Open Sesame? Open access priorities, incentives, and policies among higher education institutions in the United Arab Emirates
}

\author{
Mohamed Boufarss $^{1}$ (D) Mikael Laakso ${ }^{2}$ (D)
}

Received: 13 February 2020 / Published online: 8 June 2020

(c) The Author(s) 2020

\begin{abstract}
Higher education institutions (HEIs) have an instrumental role in the move towards Open Access (OA) by shaping the national strategies, policies, and agendas. This study sets out to explore the role of HEIs in the United Arab Emirates (UAE) OA uptake and reflect on the ongoing international initiatives pushing for universal OA to research. The study is based on an online survey targeted at UAE higher education institutions research management units. In order to measure the institutional views, only one response was solicited from each institution. A total of 19 valid responses were received, making up $47 \%$ of HEIs included in the population of organisations. Our results suggest that there is low commitment to OA among UAE HEIs as attested by the low number of OA policies, scarce OA funding, limited proliferation of institutional repositories, perceived lack of urgency to migrate from current access models, and little consideration of OA for promotion purposes. The study is the first of its kind in the UAE, Arab and Middle Eastern countries, providing rare insight into a growing phenomenon that is global, yet most vocally discussed from a western perspective and context. The study contributes to the debate on the role of HEIs in the transition to OA and in shaping national and regional OA policies, as well as informing international initiatives about the current status of $\mathrm{OA}$ in the region.
\end{abstract}

Keywords Open access $\cdot$ Scholarly publishing $\cdot$ Research universities $\cdot$ Open access policies

Electronic supplementary material The online version of this article (https://doi.org/10.1007/s1119 2-020-03529-y) contains supplementary material, which is available to authorized users.

Mohamed Boufarss

Mohamed.boufarss@tuni.fi

Mikael Laakso

Mikael.laakso@hanken.fi

1 Faculty of Information Technology and Communication Sciences, Tampere University, Tampere, Finland

2 Department of Management and Organisation, Hanken School of Economics, Helsinki, Finland 


\section{Introduction}

Around a decade ago, Ofek (2011) stated that "Today...the spirit of science in the Muslim world is as dry as the desert". Anecdotal statements such as this referring to the low scientific research and publication output in the UAE are often made within academia and beyond as people believe that the heydays of Arab civilization and scientific prosperity are long gone. There is, however, increasing evidence that scientific research is gaining strength in the UAE. The steady advancement of the UAE in international rankings and indexes such as QS World University Rankings and Global Knowledge Index, as well as promising UAE initiatives that aim to boost scientific research output are a testament to this change (Quacquarelli Symonds Limited, 2019; Times Higher Education 2019). As higher education institutions (HEIs) in the UAE increasingly compete with their international counterparts, engagement and involvement in scholarly communication initiatives such as open access (OA) seems inevitable. The UAE makes for an interesting context since research is growing and being shaped nationally at a time when possibilities for OA have become available.

OA, where access to research articles or monographs is provided online for free, has been seen by some as a path to break free of the increasingly expensive current readerpays or double-dipping models while also unlocking access to research publications for an unlimited audience (King and Alvarado-Albertorio 2008). At the detailed level, many mechanisms could lead to publications becoming available OA, but traditionally a distinction between two different OA routes is made. Gold OA, where the publication is made OA on the web directly by the publisher, often through the payment of an article processing charge (APC) (Esposito 2016). In Green OA, however, free access to the publication (often in accepted manuscript format) is provided through a repository or the author's or institutional website. As this model has the potential to achieve OA targets, researchers' attitude toward the use of APCs to advance OA remains ambivalent.

Universities around the world have seen mounting pressure from national and international science policy, and to an increasing degree research funders, to provide open and equitable access to research outputs. Reactions to these demands are often framed in the form of OA initiatives and policies. Recent data from the Registry of Open Access Repository Mandates and Policies (ROARMAP) and SHERPA/Juliet reveal a high concentration of OA policies in Europe and the Americas (ROARMAP 2020; JISC 2020). The year 2012 marked the beginning of some of the strongest OA policies in the UK such as the Finch Report, Wellcome Trust reinforced OA policy, and RCUK new OA policy (Rumsey 2017). This culminated in the establishment of the Research Excellence Framework (REF 2014) and the upcoming REF 2021. Similar efforts are led by the Scholarly Publishing and Academic Resources Coalition (SPARC) in the USA. The recently enacted OPEN Government Data Act (S. 760 / H.R. 1770) and the related upcoming rumored revision of the US government OA policy aim to push towards immediate OA to all public-funded research.

As institutional and even national efforts are challenged to create radical change in scholarly publishing that transcends borders, some multi-institutional and multi-national initiatives have started to emerge. These include, among others, the European Union's H2020 Programme, Plan S, OA2020, and AmeliCA. The H2020 Programme is the European Union's main mechanism for distributing research funding which stipulates that "each beneficiary must ensure open access to all peer-reviewed scientific publications" (European Commission ..., 2017, p. 5). OA2020 is another initially European but currently global initiative that aims to boost the transformation of existing paywalled journals to OA with 
minimal additional cost (Max Planck Digital Library 2020). On the other side of the Atlantic, the Open Knowledge for Latin America and the Global South started the AmeliCA initiative in 2018 with the objective of putting academia back in charge of scholarly publishing through diamond open access, i.e. journals that are free for both authors and readers (AmeliCA 2020). Plan S, launched by a coalition of research funders (cOAlition S), is an international initiative that aims to make all research funded by cOAlition $\mathrm{S}$ funders available as immediate OA by 2021.

OA transcends the initial motivator of public good to other objectives such as boosting research impact, increasing institutional visibility, and guaranteeing long-term costeffective access to research. Mueller-Langer et al. (2020) have demonstrated that providing OA to journals boosts research output by up to $29.6 \%$. There are increasing indicators that HEIs in the UAE are striving to achieve all or some of these goals. However, a scan of existing literature reveals limited research on OA in the UAE. Tennant et al. (2016) state that "At the current stage, Open Access has become such a global issue that it is critical for all involved in scholarly publishing, including policymakers, publishers, research funders, governments, learned societies, librarians, and academic communities, to be wellinformed on the history, benefits, and pitfalls of Open Access." By studying scholarly publishing and OA in the UAE, this study will illuminate the economic, social, ethical and academic impacts of $\mathrm{OA}$ and inform future publishing policies and strategies development and implementation.

The objective of this study is to assess current awareness, support, policies, and practices related to scholarly journal publishing among UAE HEIs, particularly in relation to OA publishing. In doing so, it seeks to contribute to the ongoing debate on the global changes in scholarly publishing in general and OA in particular. Furthermore, it tries to discover what HEIs in the UAE are doing in relation to OA, including an investigation of existing OA policies and funding options available to authors to publish OA. It will also examine how HEIs in the UAE assess publications and publication activity of researchers in the context of promotion and performance appraisals of faculty.

We are in particular interested in the organizational level rather than the behaviour and attitudes of individual researchers. HEIs interface more directly with national science policy, whereas individuals can be assumed to be more concerned with more immediate and practical aspects of their work. Organisations are also not mobile, with a large part of the research conducting staff in the UAE being expats, we are concerned with better understanding the organisations who plan to remain actors in the landscape for the long term. The level of domain expertise concerning publishing needed to reflect upon the themes in focus also support the notion of gathering insights from experts being able to answer on behalf of organisations.

\section{Literature review}

\section{Scientific research environment in the UAE}

The UAE has seen a progressive increase in scientific research and scholarly publishing output in recent years as attested by different rankings and indexes. The Global Knowledge Index 2018 (UNDP \& MBRF, 2018) and Arab Knowledge Index 2016 (UNDP $\&$ MBRF 2016) have both put the UAE ahead of all other Arab countries in several categories. According to Nature Index 2018 (Springer Nature 2018), the UAE is second 
place after Saudi Arabia among Arab countries ranked in terms of the fractional count of research published between 1 and 2017 and 30 November 2018. Only the two countries have made it to the top 50 countries among Arab states in this index.

This increase in scientific research output and publications is mainly due to the UAE embarking on an ambitious program to boost education and research in STEM, and putting the country on track of the knowledge-based economy as outlined in UAE vision 2021 (UAE PMO 2014). This transition is also guided by the UAE National Innovation Strategy (UAE PMO 2015). Initiatives and programs that support these visions and strategies range from a National Agenda for Scientific Research to Preparing for a Nobel Program (Gulf News 2016).

The country counts currently over 70 officially licensed universities according to the Commission for Academic Accreditation (CAA) and the UAE Ministry of Education websites. Many of these universities are offering master's and PhD degrees (Mitterlehner 2013). Recent CAA data lists over 300 licensed master's and doctorate programs. Moreover, The National Strategy for Higher Education 2030 clearly pledges support for research by creating research oriented educational institutions and funding research output (Gulf News 2017). This commitment materialized in 2019 with the announcement of an Abu Dhabi AED 4 billion (over one billion USD) research and development fund (Sanderson \& Khan, 2019).

Although proper research infrastructure seems to be in place, some like Ryan and Daly (2018) suggest that there is a "lack of research-intensive institutions" in the country. Furthermore, Chapman et al. (2014) have underlined the absence of appropriate conditions for increased research productivity in the UAE. This is especially the case for expatriate faculty (Austin et al. 2014). A probable explanation according to numerous studies is the emphasis on teaching to the detriment of research at HEIs. For example, Austin et al. (2014) found that most faculty were on a teaching load of between 70 and $80 \%$ leaving them with little time to conduct research. In that respect, Miller, Coble \& Lusk (2013) reported a negative impact on the number of Web of Science-indexed publications among faculty with a teaching load greater than $25 \%$. Similarly, Ryan and Daly (2018) assert that focus of UAE recruiters solely on financial incentives "may be contributing to attracting the wrong type of faculty, who are less likely to be high performing researchers."

Another major issue facing research in the UAE is the transient nature of the academic workforce. In 2017, the share of UAE nationals in the total workforce across all sectors stood at only $7.19 \%$ (UAE PMO 2019). This is reflected in the percentage of teaching staff at UAE universities. Spender and Bardsley (2009) state that “all of Zayed University's 265 academics, nearly all the 1,092 academic staff at the Higher Colleges of Technology and 570 out of 747 academics at UAE University were expatriates." Similarly, a GFH (2016) report states that expatriate faculty represented " $92 \%$ and $98 \%$ in public and private universities respectively" in 2014. Within this context, Ryan (2017) concludes that as stability of funding, personnel, and strategies are the cornerstone of research, "stability is not a characteristic of higher education institutions in the UAE." Instability of funding emanates from the country's limited expenditure on R\&D amounting to a mere $0.96 \%$ of GDP in 2016 according to the most recent World Bank data.

Finally, the UAE is facing the same challenges as other Arab countries when publishing research. Nasser \& Abouchedid (2001) believe that the development of local Arab journals is shackled by academic favouritism and nepotism, low financial support for research, limited number of local journals, low international circulation, limited freedom of academic expression, and tendency to serve mostly affiliated or local authors. Lages, Pfajfar, 
\& Shoham (2015) have outlined further issues associated with publishing on the Middle East in international journals as

" a limited number of region studies to draw from, limited exposure to international scholars' work and lack of competent collaborators, a need for high-quality writing, and difficulty in becoming members of "in-clubs" in the West".

\section{Researcher appraisal and incentives}

\section{Tenure and promotion}

Criteria often used by institutions to appraise faculty and researchers' applications for promotion and tenure can vary from one institution to another depending on its own priorities (Jolson 1974). It seems, however, that the focus has recently shifted to research output as one of the main criteria for researcher assessment leading to the "publish or perish" phenomenon. As publication output has become a de facto main measure of promotion applications, some researchers are investigating the most efficient ways to assess it. A major study by Moher et al. (2018) studied 21 documents related to faculty incentives and rewards in North America and Europe. A common point among most of the documents is the use of the journal impact factor (JIF) as a measure to assess the impact of faculty to the detriment of other criteria and metrics. Bales et al. (2019) argued that tenure and promotion committees should focus on the quality of the actual publication rather than on the journal where it appeared. The San Francisco Declaration on Research Assessment (DORA) and The Leiden Manifesto are two successful initiatives that introduce new factors and measures for consideration in assessing research impact. For some countries, however, publication in a journal indexed in Scopus or WoS is viewed as a testament to the quality of the article, irrespective of JIF or article citation count (Pudovkin 2018).

While an increasing number of institutions and funders are mandating OA or encouraging researchers to provide free access to their publications, little research is available on factoring OA publications in promotion applications. Alperin et al. (2018) analyzed review, tenure and promotion documents at several Canadian and American universities to assess how the public dimension is perceived when assessing researchers work. Contrary to their expectations that emphasis will be put on OA as an embodiment of "public patronage", there is still a focus on traditional publishing venues and metrics. Worse yet, the few documents that mentioned the OA concept were warning against publishing in OA venues. Similarly, Creaser (2010) states that many researchers are skeptical of OA publications "both as authors and as users of scholarly material". Odell, Coates and Palmer (2016), however, highlighted a success story at Indiana University-Purdue University Indianapolis (IUPUI) which managed to amend promotion and tenure policies to reward OA publications. Likewise, Morais and Barrell-Damián (2019) report that over 25\% of European universities factor OA publications in faculty appraisals and promotions.

\section{Incentivizing research publications}

Ever since the UK introduced the Research Assessment Exercise (RAE) in 1986, a lot of other countries have adopted performance-based research funding systems (PRFSs) or a cash-per-publication approach to boost research publications output. Hicks (2012) identified at least 14 such PRFSs in 2010. Franzoni, Scellato and Stephan (2011) show that 
there is indeed a correlation between publication submissions and incentives especially cash bonuses. Quan, Chen and Shu (2017) conclude that some Chinese researchers can get cash rewards ranging from 30 to 165,000 USD per paper published in journals indexed by WoS. In the Arab world, the highest known cash-per publication rewards amount to 19,999, 13,733 and 5,195 USD in Saudi Arabia, Qatar and Oman, respectively (Abritis and McCook, 2017). Turkey is another country that has introduced cash rewards to increase publication output. However, while these incentives have led to an increase in the number of articles published by Turkish authors, there has been an upsurge of publications in predatory journals and conferences (Demir, 2018). Similar trends have been reported among Italian scholars of which about $5 \%$ have published in potentially predatory journals (Bagues, Sylos-Labini \& Zinovyeva, 2019). Similarly, Butler (2003) concludes that incentives have boosted Australian journal publications whereas research impact has declined simultaneously. This can be attributed to the Australian research reward system based solely on quantitative measures. PRFSs and direct incentives have their pros and cons, but there is no doubt that institutions and countries continue using them in their quest to enhance the quality and quantity of their research publications.

Chapman et al. (2014) draw a gloomy picture of the research landscape at UAE HEIs. Their research concludes that there were no incentives to do research in the country's HEIs. Similarly, Austin et al. (2014) claim that "research is typically neither expected nor emphasized." They further claim the absence of appropriate conditions to promote research productivity especially for expatriate faculty members. This research environment may be alienating research-focused faculty (Ryan and Daly (2018). The situation is somehow different in a few top public and semi-public universities where "Research is a relatively new expectation" (Chapman et al. 2014). There is also increasing evidence that some local universities are introducing financial rewards to stimulate scholarly publishing. UAEU, Zayed University, Jumeirah University and Ajman University are among the UAE HEIs that have disclosed their policies on financial rewards for research papers published in Scopus indexed journals. Badri and Abdulla (2004) claim that UAEU academic promotion process puts research on par with teaching. Similarly, the University of Sharjah's annual awards policy provides a higher financial reward for outstanding research than for outstanding teaching.

\section{Open access in the UAE}

One of the first studies that, albeit indirectly, tackled OA in the UAE was conducted by Taha (2007). This study, examining e-learning at the United Arab Emirates University, concludes that providing access to OA resources is one of the library's priorities. A couple of years later, a study of attitudes of faculty towards OA in Tunisia, Morocco, Oman and UAE by Gdoura (2009) concludes that there was high awareness of OA concepts among the respondents but little desire to auto-archive or pay APCs. Another survey of faculty attitudes towards OA and IRs at the Petroleum Institute by Boufarss (2011) reports marginal awareness of OA and little previous self-archiving experience among faculty. It also asserts that boosting self-archiving rests with institutions since respondents would comply with institutional OA mandates. A similar study by Kaba and Said (2015) at Al Ain University of Science and Technology concludes that faculty "possess a good knowledge and a positive perception of OA resources". They also found a correlation between the level of awareness or use and perception of OA resources. These findings were corroborated by Mavodza (2013) who stated that in line with the rest of the world "access to OA research 
information is appreciated, and researchers are also involved with contributing scholarly research in OA journals." Indeed, a recent scan of scholarly journals in the UAE by Boufarss (2020) reveals a prevalence of both OA journals (about $64 \%$ of all online journals) and author-pays OA model (around 75\% of OA journals charge APCs).

As early as 2009, Fitzgerald \& Olwan (2009) called on UAE institutions to develop repositories and offer incentives to researchers to provide OA to their research. However, Carlson (2015) confirms the hypothesis cited by Boufarss (2011) and Sajjad Ahmed \& Al-Baridi (2012) that OA and institutional repositories (IRs) in the Arab countries had remained at an "infancy stage". The study reported the existence of a limited number of repositories in the UAE and absence of related policies, mandates and clear OA guidelines. Furthermore, there were no policies listed in ROARMAP and only three repositories are listed in OPENDOAR under UAE. For the sake of comparison, a share of over $90 \%$ of Canadian research universities had an IR already in 2009, and over $80 \%$ of European universities currently have a digital repository or participating in a shared repository while a similar percentage of institutions have institutional policies on OA (Greyson et al. 2009; Morais and Borrell-Damián 2019).

With an estimated OA percentage level of $25.33 \%$ and 24\% in 2017 and 2018 (Scimago, 2019), the UAE is at par with most other countries. It can be argued, however, that these figures are justifiable given that the UAE is a country that is just a little over two decades old and that Scimago does not include all local and regional journals. The Emirates Publishers Association was not created until 2009 and even though the country's publishing plan as laid out by Al Qasimi (2017) does not specifically touch on scholarly journal publishing, it is a very ambitious program and aims to make of the UAE a publishing industry world leader.

\section{Controversial issues in $\mathrm{OA}$}

Some of the highly debated aspects associated with OA include APCs, predatory journals and academic social networks (ASNs). The rising APCs, predatory publishing creating hesitation about even new legitimate journals, as well as ASNs facilitating infringement of copyright led many to argue against OA funding and its institutional or governmental support.

Even though most OA journals do not charge any publication fees (Crawford 2019; Johnson et al. 2018), there is increasing evidence that OA publishing based on author-side payments, so called article processing charges (APCs), is taking off. The upsurge in OA in the UK between 2009 and 2016 was attributed to the support of APCs and Gold OA (Larivière and Sugimoto 2018). Correspondingly, the total global revenue from APCs was estimated at over 649 million dollars in 2018 (Crawford 2019). However, publishing OA articles in hybrid journals without publishers adjusting subscription fees to offset the APCs would lead to double dipping (Björk and Solomon 2014, 2014b). Furthermore, APCs can disadvantage authors with limited funding, especially from developing countries (Shah and Gul 2013; Tenopir et al. 2017). Mischo and Schlembach (2011) have also reported concerns over APCs with regards to "cost to authors, ... and journals expanding article acceptances to make money". Moreover, APC payments fall mostly on authors or their funders and the majority of the few institutions covering APCs use existing library budgets rather than additional allocated funds (Bauer et al. 2013; Lara 2014; Fernandez and Nariani 2011). 
Nothing captures the current state of researchers' scramble to publish at all costs better than the Goodhart law as phrased by Marilyn Strathern: "When a measure becomes a target, it ceases to be a good measure." Blind focus of academic institutions on quantitative metrics for faculty appraisals is pushing the latter to fall prey to what Beall (2012) and Anderson (2012) dubbed as "predatory publishers". The share of articles published by alleged predatory journals had increased from 53,000 to 2010 to an estimated 420,000 articles in 2014 (Shen and Björk 2015). However, these journals will likely have minimal impact as recent analysis by Björk, Kanto-Karvonen and Harviainen (2019) has shown that most of the articles they publish receive little to no citations.

Demir (2018) claims that the UAE is one of the top ten countries with predatory journals listed in Beall's now defunct list of predatory journals. Furthermore, the editor of an OA journal published in the UAE had to resign after the journal accepted a hoax article for publication against a fee (Gilbert 2009). While no research could be identified on the number of articles published by UAE authors in predatory journals, the presence of predatory publishers in the country may be a tell-tale sign of a response to an existing demand.

Björk (2017), talks about an even more radical and disruptive trend in OA he refers to as "black OA". He defines it as the illegal access provided by social sites or piracy-based platforms to millions of pay-walled articles. ASNs such as ResearchGate and Academia.edu are disrupting traditional academic publishing models by providing authors with alternative means to share and access research articles (Laakso et al. 2017; Lovett et al. 2017) often in clear violation of copyright laws and author-publisher agreements. Laakso and Polonioli (2018) labelled ASNs as a catalyst of copyright infringement. Indeed, Jamali (2017) suggests that $51.3 \%$ of articles posted in ResearchGate breached copyright and publishers' OA policies. Similarly, Himmelstein et al. (2018) claim that Sci-Hub, a widely criticized academic content platform for hosting pirated content, provides free access to $85.1 \%$ of all articles otherwise available only behind paywalls. Moreover, even in the presence of an IR, researchers are increasingly opting to share their research through ASNs (Lovett et al. 2017). Borrego (2017) conclusively shows a notable disparity between Spanish authors' deposition of articles in their IRs and in Research Gate with $11.1 \%$ and 54.8\%, respectively. Furthermore, Laakso and Polonioli (2018) state that IRs scored "second lowest" among eight different web locations for dissemination of research articles. Harle (2016), for his part, sees that the uptake of piracy-based alternatives is inevitable if access costs are not cut especially for the developing world.

\section{Method}

\section{Institutions}

The primary aim of this multi-institutional study was to investigate scholarly publishing and OA practices in the UAE. Preliminary analysis of WoS ResearcherID affiliations revealed that most researchers work for universities. Thus, the study focuses on HEIs deemed to have measurable research output. To determine which institutions are researchintensive or have some assessable research productivity, the Commission for Academic Accreditation list of higher education institutions, Scimago Institutions Rankings, QS World University Rankings, and Web of Science researcher affiliations were analyzed.

A total of 50 institutions offering masters and $\mathrm{Ph} . \mathrm{D}$. degrees were initially identified. 10 institutions were removed because a direct contact could not be identified, their website 
did not provide any indication of ongoing research or interest thereto, or the institutions are branch campuses of international institutions with no local research administration offices. A final population of 40 institutions was selected. We then created a contacts list of the key personnel in charge of/or involved with research at those institutions. These contacts were selected from the HEIs research administration offices whenever that was possible. In the few cases where a research in-charge could not be identified, the heads of academic departments or librarians were added to the contact list. These respondents were solicited to forward the survey to any staff better suited to respond on behalf of their university. All contact information was gathered from the entities' websites. All institutions meeting the research component criteria above were invited to take part in this survey.

\section{Data collection procedure}

This study used a multi-institutional quantitative online survey as the main instrument to collect data. The survey consists of 42 , mostly close-ended, questions. The questions in the survey were informed by instruments in previous studies namely Greyson et al. (2009), Creaser (2010), Miller, et al. (2013), Bauer et al. (2013), Lara (2014), Fernandez and Nariani (2011), Morais and Borrell-Damian (2018), Kipphut-Smith et al. (2018), Beshyah et al. (2018), and Bales et al. (2019). The questions were, however, extensively customized to fit around the areas this study is addressing. As the survey seeks to provide a bird's-eye view of scholarly articles publishing and OA in the UAE HEIs, it was split into sections, namely: general demographics, scholarly publishing, OA policies, APCs and OA funding, incentivizing research, researcher promotion and publishing output, IRs and self-archiving, and awareness of predatory journals.

The survey was created and administered using Surveymonkey. Responses were solicited between May and October 2019. It was tested by the researcher and several colleagues for any content or technical issues before being distributed. The survey instrument is provided as Appendix 1. A personalized email invitation with a link to the online survey was sent to all persons listed in the HEIs contact list. Only one response was solicited per institution. In line with "the ethical principles of research with human participants and ethical review in the human sciences in Finland" (TENK, 2019), our survey invitation included a summary of the study, an informed consent, ethical reassurances, and the right to withdraw from the study. Reminder emails, slightly reformulated from the initial invitation, were sent at weekly intervals to non-respondents. By the end of the survey period, data was collected from 19 universities. The anonymised responses are available as a dataset in Zenodo (Boufarss and Laakso 2020).

\section{Results and discussion}

Of the 40 invitations sent, we received a total of 19 responses. The overall response rate was around 47\% (63\% of private universities, and 37\% public universities). Respondents on behalf of their institutions included research administration directors, academic managers, deans, and librarians.

This part of the study presents and discusses the results of the multi-institutional survey. In line with the survey structure, it is divided into six sections, each of which presents the responses to the related set of questions. 


\section{State of scholarly publishing}

This section focuses on questions pertaining to the size of the researchers' population, number of scholarly articles published, peer-reviewed journals, languages of publication, and strategies for boosting research productivity.

Table 1 shows that over a third of responding institutions have between 20 and 50 researchers. $26 \%$ of the institutions have between 50 and 100 and a similar percentage of institutions have over 100 researchers. Almost $50 \%$ of private institutions have between 20 and 50 researchers.

In response to a question on scholarly articles published by all researchers in the last 12 months, most of the 14 responding institutions indicated that about $80 \%$ of all articles published by their researchers were in subscription-based journals with an overall average of 73 articles versus only 18 in OA journals (Table 2).

When asked if the institution publishes a peer-reviewed journal of its own, almost $73 \%$ (11) responded negatively. 50\% (2) of the institutions that were involved in journal publishing indicated that their journal(s) were OA.

When asked about the approximate percentage of staff publications in non-English-language journals, the highest percentage given was 15 and the majority of the institutions that responded to this question indicated $0 \%$. A further related question on the preferred and encouraged publication channels (Fig. 1) revealed strong preference for international English-language journals and Scopus or WoS indexed journals with over $80 \%$ of

Table 1 Size of researcher population $(n=19)$

\begin{tabular}{lll}
\hline Fewer than 20 & $10.5 \%$ & 2 \\
$20-50$ & $37 \%$ & 7 \\
$50-100$ & $26 \%$ & 5 \\
More than 100 & $26 \%$ & 5 \\
\hline
\end{tabular}

Table 2 Number of articles published in OA and paywalled journals in the last 12 months $(n=15)$

\begin{tabular}{llc}
\hline & Average number & Total number \\
\hline Open access journals & 18 & 249 \\
Subscription-based journals & 73 & 1028 \\
\hline
\end{tabular}

International English language journals

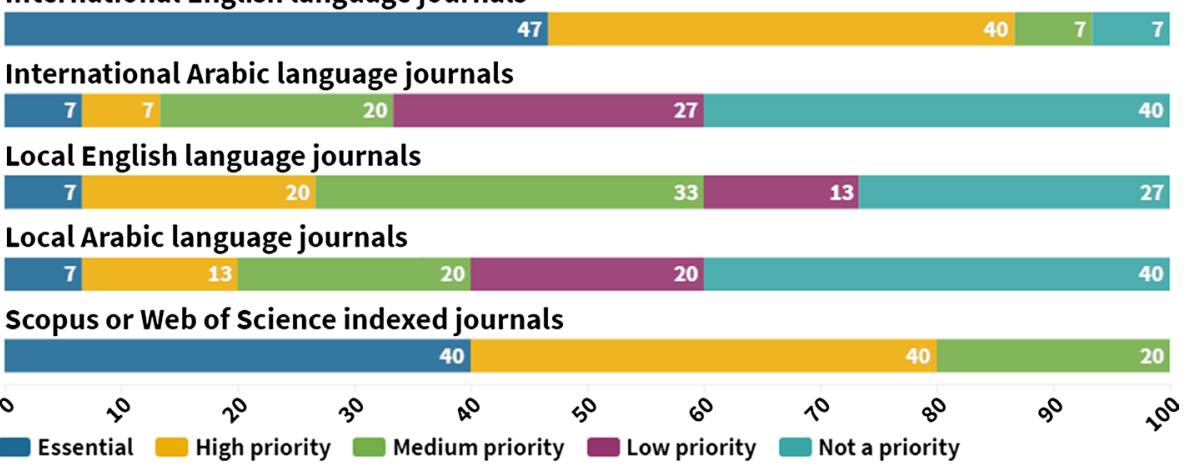

Fig. 1 Favored and encouraged publication channels by languages $(n=15)$ 
Table 3 Strategies to boost research productivity $(n=15)$

\begin{tabular}{lcc}
\hline Recruit faculty members who have extensive research experience & $67 \%$ & 10 \\
Allocate time for faculty to work on internal and external research projects & $53 \%$ & 8 \\
Create research centers in different disciplines & $33 \%$ & 5 \\
Provide research related training and professional development & $53 \%$ & 8 \\
Organize conferences and symposiums & $53 \%$ & 8 \\
Establish a publication support unit & $13 \%$ & 2 \\
Establish a researcher reward program & $27 \%$ & 4 \\
Link promotion with publication records & $60 \%$ & 9 \\
Setup research teams & $33 \%$ & 5 \\
Integrate research components in the curriculum to stimulate student's contribution & $47 \%$ & 7 \\
$\quad$ in research activities & $73 \%$ & 11 \\
Encourage institutional, national and international collaboration & $20 \%$ & 3 \\
We do not have any particular strategies to increase research productivity &
\end{tabular}

the institutions considering these "essential" and "high priority". On the other hand, both international and local Arabic-language journals were in the majority of responses reported as "not a priority" or "low priority". In contrast, local English-language journals were looked at more positively with nearly $60 \%$ indicating these as "essential", "high priority", and "medium priority". These trends resonate with Al-Aufi's (2012) conclusion that Arab scholars have been found to shun local and Arabic journals.

The majority of the institutions that responded to a question on strategies adopted by their institution to encourage and promote research productivity put emphasis on research collaboration (73\%), recruiting faculty with research experience $(67 \%)$, and linking promotion with publishing records (60\%). The least emphasized strategies include "establishing a publication support unit" (13\%) and "establishing a reward system" (27\%). $20 \%$ of the institutions indicated that they do not adopt strategies to increase research productivity (Table 3).

\section{Open access policies}

The second section of the survey was concerned with institutional OA policies, perception of OA, and features of OA policy.

More than $73 \%$ of the respondents to a question on familiarity of the term "Open Access" as applied to research indicated that they have a clear idea of what OA is. This percentage is in line with findings by Greyson et al. (2009) who reported that $66 \%$ of their respondents had a clear idea of what OA stands for. A further $20 \%$ stated that they were OA experts in stark contrast to Greyson et al. (2009) conclusion that only $11 \%$ of librarians and none of the research administrators reporting to be experts in OA. A further 7\% stated that they have some idea of what OA is about. This is again in contrast with the higher percentage reported among Greyson et al. (2009) respondents. It can be argued that these disparities can be attributed to the increasing awareness of OA and OA becoming mainstream since 2009.

When the universities were asked about the strategic importance of OA for different university stakeholders, Fig. 2 shows that it has high or moderate importance to all of them. However, it holds the highest importance for librarians followed by early stage researchers than for any other university stakeholders. One may claim that this is because libraries are bearing the burden of buying subscriptions at a time of dwindling budgets. Surprisingly, 


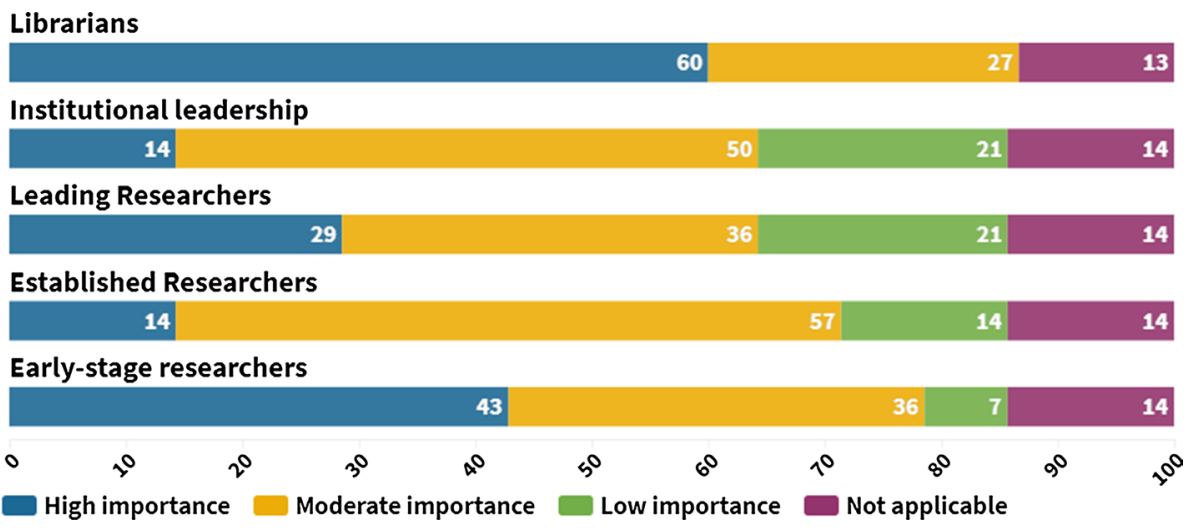

Fig. 2 Strategic importance of OA for different HEI stakeholders $(n=15)$

OA has a low importance for leading researchers and institutional leadership at $21 \%$ (3) each. The EUA survey (Morais \& Borrell-Damian 2018) found OA to be" important or very important for all professional groups" especially for institutional leadership.

Responses to a question on the availability of an OA policy indicate that only a mere 7\% of institutions have an OA policy. A further $13 \%$ are planning a policy to be released in the next 12 months. Another 27\% have plans in place for an OA policy but not in the next 12 months. However, 53\% indicated that they are not planning to develop an OA policy. These findings are in stark contrast to the results from Morais \& Borrell-Damian (2019) European survey which reveals that over $60 \%$ of HEIs have an OA policy in place and a further quarter were developing one and only $12 \%$ don't have an OA policy. Similarly, KipphutSmith et al. (2018) reports that nearly $90 \%$ of the surveyed COAPI institutions have an OA policy. This anomaly may be related to low awareness of OA, absence of self-archiving infrastructure or strategic vision.

$86 \%$ of those institutions with an OA policy stated that its main purpose is to encourage researchers to self-archive their publications. A further $71 \%$ indicated that its main objective is raising awareness of OA. $43 \%$ indicated financial support of OA publishing as an element in their OA policy. $57 \%$ of the respondents have a mandate element in their policy. The order of importance reported here matches that showcased by Morais \& BorrellDamian (2018) among EU universities with the exception of the financial support element that scored second lowest among UAE HEIs. This could be attributed to rampant absence of financial support for OA in the UAE. However, these findings are contradicting Kipphut-Smith et al. (2018) who state that about a quarter of their respondents have an encouragement $\mathrm{OA}$ policy and that over half have a rights-retention mandate requiring authors to deposit in an IR upon acceptance of the article for publication.

When responding to a question on motives for the OA policy, all institutions cited higher research impact as a main motive. This is closely followed by "increasing institutional visibility" and "long-term cost-effective access to research". "Greater public engagement" surprisingly came at the bottom of the list. Only $29 \%$ cited "receiving more funding" as a motive. Similarly, only $43 \%$ listed "unlocking knowledge to the whole world" as a motive. These figures are in agreement with EU universities responses in terms of a strive for higher research visibility and impact (Morais and Borrell-Damian 2018). 
Table 4 Existence of an institutional OA policy

Does the university have an institutional OA policy? $(n=15)$

Yes

$7 \%$

$13 \%$

My institution is in the process of developing an Open Access policy (and expects to have one in place within 12 months)

My institution is planning to develop an Open Access policy (but does not expect to have $27 \%$ a policy in place within 12 months)

My institution is not planning to develop an Open Access policy

Elements of the OA policy $(n=7)$

Encouragement policy, recommending researchers to deposit publications in an institutional/shared repository

Awareness raising, including training for early-stage researchers on open access to research publications

Financial support for researchers to publish their papers in open access

Mandate: researchers deposit publications in a repository and make full text open access within a specified time period

Mandate: researchers deposit publications in a repository, this requirement being linked $\quad 57 \%$ to internal performance evaluation

Mandate: researchers deposit publications in a repository, this requirement being linked $57 \%$ to an external, national review procedure

Mandate requiring publication in open access (gold route/gold open access)

$0 \%$

$43 \% \quad 3$

$57 \% \quad 4$

Motives for instituting an OA policy $(n=7)$

Increasing institutional visibility

Higher research impact

$100 \% \quad 7$

Greater public engagement

$14 \% \quad 1$

Unlocking knowledge to the whole world

Long-term cost-effective access to research findings

Receiving more funding

$29 \%$

5

Other (please specify)

$0 \%$

Extent of satisfaction with current access model $(n=15)$

We are satisfied with the current subscription-based access model and open access is not $7 \%$ a priority for us

We are satisfied with the current access model, but endorse open access

We are not satisfied with the current subscription-based access model and made open access a priority

We are not satisfied with the current subscription-based access model, but open access is $20 \%$ not a priority for us

Other (please specify)

In response to a question on satisfaction with the current access model, the majority reported that they are satisfied with the current access model but are endorsing OA. It is surprising that $\mathrm{OA}$ is low on the agenda of the responding HEIs even among those not satisfied with the current access model. As the majority of universities in Europe are exerting efforts to revise subscription contracts in support of OA and APCs (Morais and BorrellDamian 2019), further research is required to verify if this is due to availability of enough funds to libraries in the UAE, purchase of limited resource packages by the libraries due to low researcher pressure, reliance on pirated content, or any other reasons (Table 4). 
Table 5 OA funding among UAE HEIs

Sources of OA funding $(n=15)$

Funds specifically included in research funding

\begin{tabular}{ll}
$53 \%$ & 8 \\
$33 \%$ & 5 \\
$7 \%$ & 1 \\
$27 \%$ & 4 \\
$27 \%$ & 4 \\
$0 \%$ & 0 \\
$7 \%$ & 1 \\
\hline
\end{tabular}

Indirect costs administered at faculty/ department level

Indirect costs administered centrally

Authors own resources e.g. discretionary funds

No mechanism to support author pays

Other

Don't know 1

Reasons for instituting OA funding $(n=12)$

Faculty requests

Provides incentives for authors to publish open access

Supports alternative models of scholarly publishing

Part of campus-wide strategy to promote OA

Maximises the impact of institution's research

Fosters experimentation with new initiatives

Supports public access policies

Other (please specify)

$8 \%$

Types of OA publications covered by funding $(n=12)$

All peer-reviewed open access journals

Open access journals from the Directory of Open Access journals

OA journals from specific publishers through institutional memberships

Subscription journals offering open access options (hybrid)

Not applicable

Other forms of OA publication (please specify)

$17 \%$

Reasons for not paying APCs $(n=10)$

We don't have a budget to support APCs

$\begin{array}{ll}70 \% & 7 \\ 10 \% & 1 \\ 10 \% & 1 \\ 0 \% & 0 \\ 0 \% & 0 \\ 60 \% & 6 \\ 10 \% & 1\end{array}$

\section{OA funding}

This section of the survey looked at OA funding aspects such as OA funding policy, APC funding resources, motives for OA funding, publications covered by funding, motives for non-payment of APCs (Table 5).

In a response to a question on the existence of an OA funding policy in the institution, over $73 \%$ of the HEIs reported that they do not have a policy to fund OA. Only $13 \%$ of all universities have a policy for funding OA. There is no significant difference between private and public institutions in this aspect. These figures are in stark contrast to the situation in Canada where a quarter of respondents have an OA funding policy in 
place, nearly a further third have one under review, and around $44 \%$ don't have a policy (Fernandez and Nariani 2016). This could be attributed to the perception of OA as low quality or merely to the fact that it is not a priority in the UAE.

Respondents were asked about sources of funds to support OA. Consistent with Creaser (2010), the majority (53\%) of HEIs reported funds earmarked as part of research funding as the main source. Another third, against 15\% reported by Creaser (2010), listed indirect costs administered under departments or research units. A further $27 \%$ listed authors' own resources as a source of funding. A similar percentage said that they do not have a mechanism in place to support OA funding. However, both UAE and Canadian figures are inconsistent with findings of Lara (2014) which report that nearly half of the respondents listed the author's own resources as the main source of APCs.

When asked about the reasons for instituting OA funding, 67\% of HEIs reported "Supports alternative models of scholarly publishing" as the main reason. This was followed by "Maximizes the impact of institution's research" and "Faculty requests" with 50\% and 42\%, consecutively. However, none of the responding institutions selected "Part of campus-wide strategy to promote OA" as a reason. These findings are partly consistent with the conclusions of Fernandez and Nariani (2016) who concluded that support of alternative models was the main reason for OA funding and campus-wide OA strategy being the least important reason.

In terms of the types of OA publications covered by the funding policy, there seems to be no significant differences between publications incentivized by the UAE HEIs. This may signal a low understanding or awareness of nuances between different OA models as well as DOAJ. Some of these data is inconsistent with Fernandez and Nariani (2016) who reveal that hybrid OA is the least supported channel. For Canadian libraries, DOAJ-listed journals seem to be privileged with $35 \%$ of respondents stating that they cover their APCs.

In response to a question on the reasons the institution did not pay any APCs, over two thirds of the respondents reported that they do not have a budget to support APCs. $60 \%$ indicated that the decision on the publishing venue rests with the authors. Surprisingly, $10 \%$ reported that they prefer their authors to publish in paywalled journals, they perceive paywalled journals to have higher impact, and are not familiar with OA publishing venues. However, it is interesting that none of the respondents perceive OA journals to have lower prestige or having lower peer review practices.

\section{Self-archiving and Institutional Repositories}

Questions in this section cover self-archiving and IRs aspects namely: availability of IRs, self-archiving preferences, department in charge of IR and self-archiving, and factors affecting self-archiving decisions.

In stark contrast with previous studies (Carlson, 2015 and OPENDOAR, 2018), only a little over half of the responding universities reported having an IR. This number remains well below the over $80 \%$ of European universities (Morais and Borrell-Damián, 2019) and the over $90 \%$ of Canadian research universities (Greyson et al. 2009) which reported having a repository of their own or participating in a shared one.

Similar to Creaser (2010), IRs are the most prominent location where self-archiving is required or recommended. $43 \%$ (3) of the responding UAE universities mandate it and the remaining $57 \%$ (4) are encouraging it. While a similar number encourage using subjectbased repositories, about 29\% (2) tolerate it. An equal percentage (43\%) encourage and tolerate using author-project websites. Surprisingly, about $14 \%$ (1) require self-archiving in ASNs while a further 29\% (2) and 43\% (3) encourage and tolerate it, respectively (Fig. 3). 


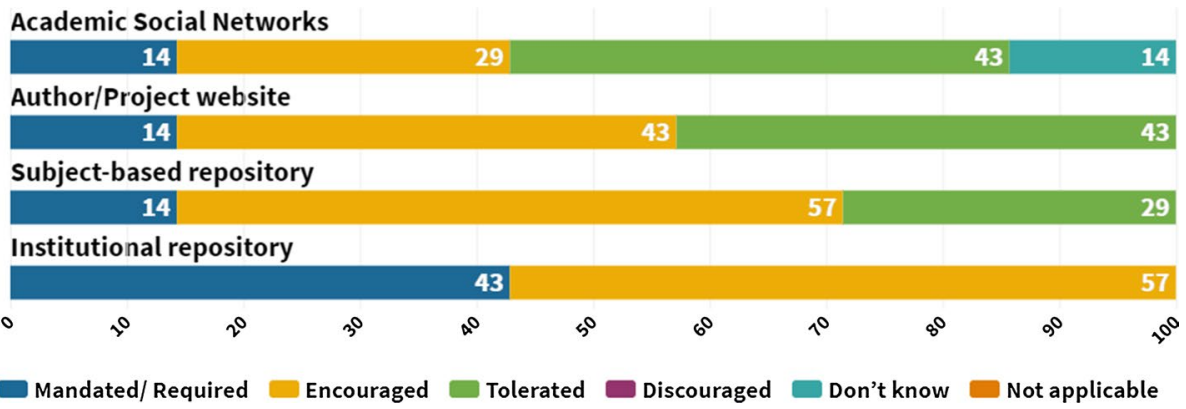

Fig. 3 Self-archiving channels perception at the institution $(n=7)$

Table 6 Who oversees the IR? $(n=7)$

\begin{tabular}{lll}
\hline My university does not have an Institutional Repository & $29 \%$ & 2 \\
University IT/Campus computing services department & $14 \%$ & 1 \\
University library & $86 \%$ & 6 \\
Maintenance is contracted out to a commercial firm & $14 \%$ & 1 \\
Not sure & $14 \%$ & 1 \\
Other (please specify) & $29 \%$ & 2 \\
\hline
\end{tabular}

\begin{tabular}{lr} 
Author at home institution & 57 \\
\hline Lead author at any institution & \\
\hline 14 & 57 \\
\hline Library & \\
\hline
\end{tabular}

Provost's office

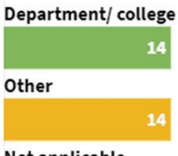

Not applicable

$2^{\circ} \quad 3^{\circ} \quad 0^{\circ} \quad 5^{\circ} \quad 6^{\circ}$

$6^{\circ} \quad 1^{\circ} \quad 8^{\circ} \quad 9^{\circ} \quad 2^{\circ}$

Fig. 4 Who is in charge of self-archiving at the HEI? $(n=7)$

We then asked universities about the department that oversees their IR. The university library was predominantly selected as the department managing the IR. Around 14\% stated that their IT unit is in charge of the IR. A similar percentage reported that the management of their IR was outsourced (Table 6).

In-line with Kipphut-Smith et al. (2018), around 57\% (4) of HEIs selected the library and author at home institution as the primary units responsible for depositing articles equally (Fig. 4).

In response to a question on the importance of factors for encouraging self-archiving, HEIs regard increasing citations as the highest important factor followed equally by 


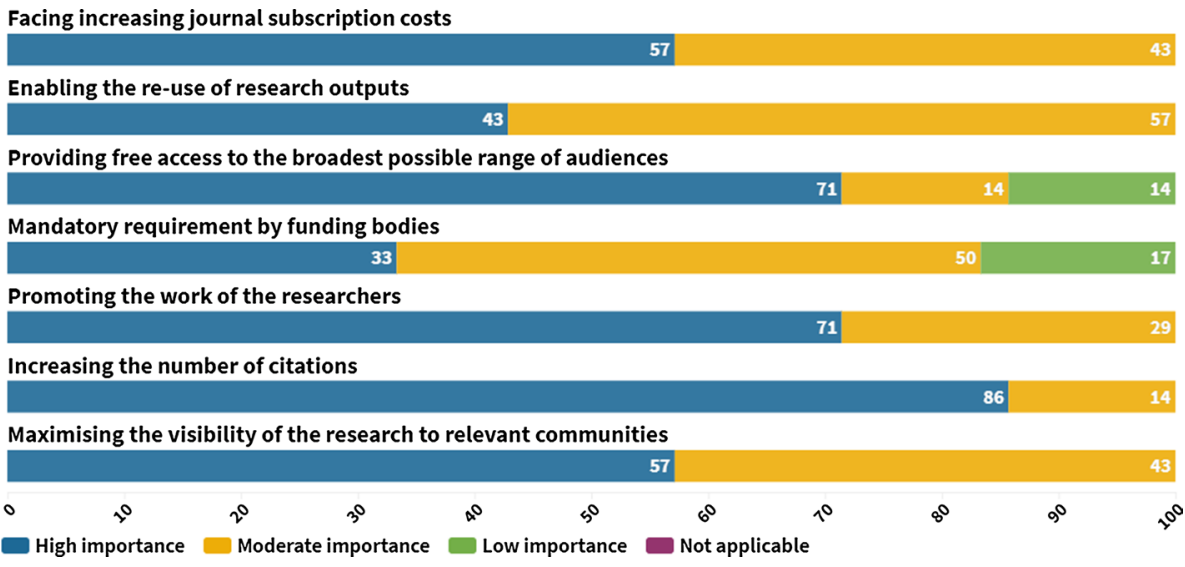

Fig. 5 Important factors for encouraging self-archiving $(n=7)$

promoting the work of the researchers and providing free access to the widest audiences (Fig. 5). Unlike in European universities where "mandatory requirement by funding bodies" was viewed as an important factor (Morais and Borrell-Damián 2018), it scored lower in the UAE. This can be attributed to the absence of OA-mandating funding mechanisms, policies, and procedures in the country.

\section{Incentives for $\mathrm{OA}$}

The aim of this section was to elicit responses on questions related to publication records for tenure and promotion, tracked and valued metrics, perception of OA articles for promotion purposes, types of incentives, incentivizing OA publication, education on OA, and incentivized journals.

To the question of "Does the institution take publishing records into account for tenure and promotion purposes?" over half of the institutions responded (8) answered that they take publication records into account for promotion while a surprising $29 \%$ (4) said it was only occasionally done. An unexpected $14 \%$ (2) said that they do not take publication records into account during tenure and promotion evaluations.

The high percentage of universities tracking and valuing the JIF and a low number selecting altmetrics is a suggestion that UAE HEIs like many universities around the world have not yet embraced the calls of initiatives such as DORA and The Leiden Manifesto that call for more diverse ways of evaluating research output (Fig. 6). Even though still widely used to assess researchers, use of JIF has been widely criticized (Kurmis, 2003; Vanclay, 2009; Moher et al. 2018).

While the majority of HEIs $(79 \%-11)$ reported a neutral position towards OA publications during tenure and promotion assessment, only about a fifth (3 HEIs) look at them positively. This may be associated with low awareness of the public good dimension of OA as well as OA being low on the HEIs priorities list.

Two thirds of the universities (8) have tied publication output with priority in promotion. Nearly $42 \%$ (5) reward researchers with extra funding for research. Around $17 \%$ (2) are catching up on the global trend of cash-for-publication as shown by Abritis and McCook (2017) either in the form of direct cash bonuses or by providing salary 


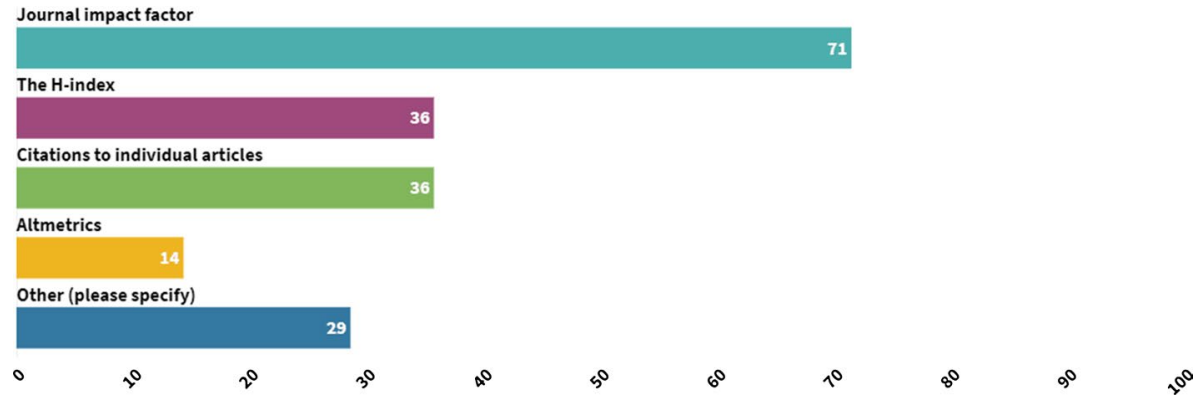

Fig. 6 Tracked and valued metrics $(n=14)$

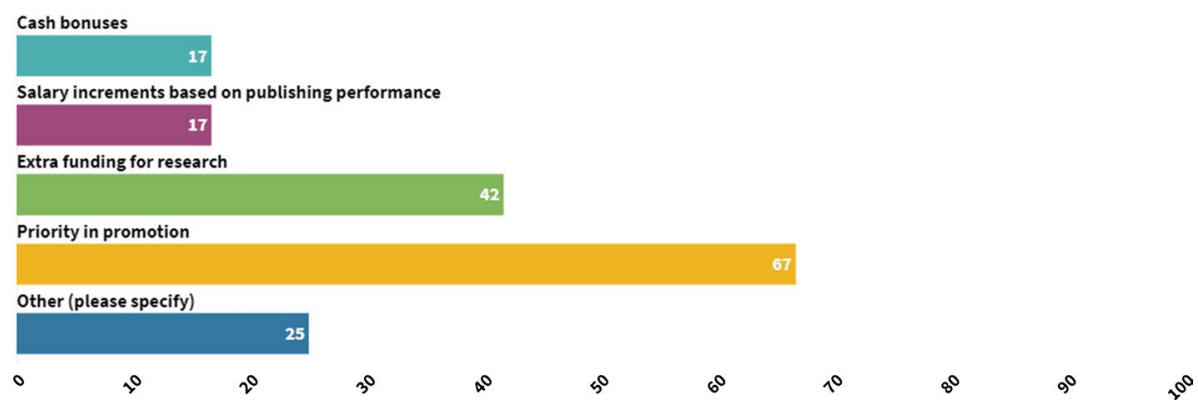

Fig. 7 Types of incentives given to researchers to publish $(n=12)$

increments. Free text responses falling under "other" response choices include conference attendance funding for prolific researchers. These results may be somehow contradictory to the researchers' expectations. In a survey by Miller, Coble \& Lusk (2013), most of the researchers prefer "merit-based salary raises" as an incentive. Similarly, Franzoni, Scellato \& Stephan (2011) demonstrated a positive impact of cash bonuses on publication output (Fig. 7).

Our survey results show that OA is low on the UAE HEIs agendas as only about $8 \%$ (1) of the organizations offer their researcher incentives to publish OA. About two thirds (8) responded that they do not incentivize publishing OA while a quarter (3) did not know if their institution does or not.

When asked about the kind of OA education they offer their research communities, three quarters of the universities stated that they do not provide any (Fig. 8). Only about $17 \%$ (2) provide direct training in the form of lectures and information sessions. A similar number distribute printed brochures and pamphlets about OA. Only about $8 \%$ (1) have a webpage about OA. These findings conflict with Greyson et al. (2009) who found that about $58 \%$ of the library respondents were offering OA lectures and that $63 \%$ were providing printed materials promoting OA.

Free text responses to a final question on any particular journal rankings or lists (such as Web of Science, Scopus, ABDC Journal Quality List, Harzing or ABS Journal Guide) that are perceived as important by the institution and incentivizes researchers to publish in show a predominance of Scopus as a reference list. 


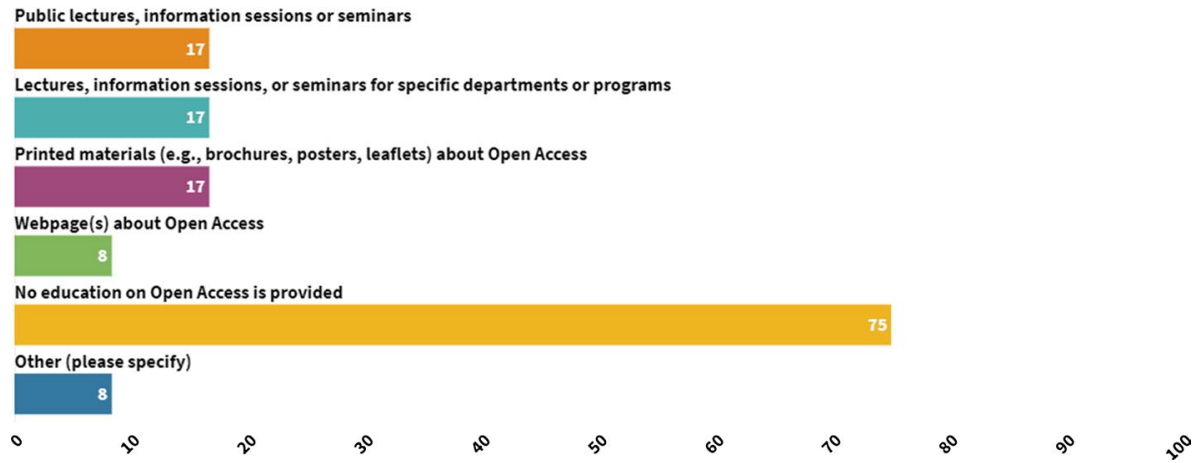

Fig. 8 Education on OA for research community $(n=12)$

\section{Predatory journals}

In the final part of the survey, HEIs were asked five questions on their awareness and perception of predatory journals and articles in predatory journals.

In response to a question on their familiarity with predatory journals, half of the respondents (6) stated that they are fully knowledgeable of the concept. A further third (4) reported that they are fairly familiar with it. Only $17 \%$ (2) did not have a clear idea about predatory journals. This is consistent with Beshyah et al. (2018) who discovered that nearly half of their respondents had never heard of (32\%) or have a faint idea (18 and $11 \%$ ) about predatory journals.

Regarding difficulty in distinguishing predatory from legitimate OA journals, a third of the HEIs (4) indicated that it was easy. However, in line with Beshyah et al. (2018), $42 \%$ (5), 17\% (2) and $8 \%$ (1) expressed the belief that it was somewhat difficult, difficult, and extremely difficult, respectively.

In terms of excluding publications in predatory journals during promotion applications evaluation, 25\% (3) of HEIs stated that they did. A third (4) indicated that they did only if the journal was not listed in Scopus or WoS. Surprisingly, about $8 \%$ (1) reported not excluding them and a further third (4) stated they were not aware of predatory journals.

Concerning the availability of a list of journals perceived as predatory in the HEI, only a little over $17 \%$ (2) indicated that they have while a third (4) reported that they don't. Half of the respondents (6) said that they are not sure. In contrast, $79 \%$ of Bales, et al. (2019) respondents stated they don't and $8 \%$ said they do. Given that only $13 \%$ of their respondents were not sure that a list existed against half of this survey's respondents, the percentage of HEIs keeping a list is proportionate.

In response to a final question on whether publishing by a tenure and promotion candidate in a journal on this list influences how their publication is perceived, half (4) of the responding HEIs believe it does. Similarly, Bales, et al. (2019) found that the majority of their respondents looked sceptically at publications in such journals during tenure and promotion evaluations. 


\section{Conclusions}

The results of this survey suggest that there seems to be a generally positive perception of OA among UAE HEIs, coupled with moderate adoption of OA policies and practices. However, the results also indicate that a lot still needs to be done to create a culture that is conducive for a move to a higher priority for OA adoption. All indicators point to OA being low on the UAE HEIs priorities and that considerable improvements pertaining to awareness, policies, best practices, and infrastructure are required if the share of OA publications is to grow.

In terms of the state of scholarly publishing, there is still a predominance of publications in paywalled versus OA journals among UAE HEIs in spite of reported international reversal of this trend in favour of OA (Piwowar et al. 2019). In line with international trends (Banks 2018; van Weijen 2012; Al-Aufi 2012), there is a clear preference for Englishlanguage, international journals and Scopus or WoS indexed journals at the detriment of local and Arabic-language journals. Finally, HEIs use a combination of strategies to boost research publications, mainly by promoting research collaboration, recruiting faculty with previous research experience, and linking promotion with publishing records.

The survey indicates that UAE HEIs are mostly aware of the OA concept. However, this awareness has not translated into actions as the majority of responding HEIs do not have an OA policy. In contrast, the majority of European institutions have an OA policy or in the process of adopting one (Morais and Borrell-Damian 2018). This disparity could be attributed to the fact that $\mathrm{OA}$ is high on the agenda of institutional leadership at European institutions (Morais and Borrell-Damian 2018). The majority of UAE responding HEIs reported being satisfied with the current access model, where the few existing UAE policies aim to raise awareness of OA but not mandating OA or providing APC support. Findings suggest that instituting OA policies at these institutions is mainly motivated by the desire to boost research impact and increase institutional visibility rather than by public good or sharing knowledge with the world. This aligns them with North American universities for which "public patronage" of research was a low priority (Alperin et al. 2018).

We found that some institutions do not have a policy on funding OA publishing. Sources of OA funding are mainly included in the research funding, indirect costs at departmental level and from authors' own resources. Instituting an OA policy is often driven by a desire to support alternative scholarly publishing models and maximizing research impact. In terms of types of journals, HEIs do not seem to distinguish between gold and hybrid journals when it comes to funding OA publishing.

Although over half of the HEIs now have an IR, this remains a subpar achievement compared with $80 \%$ of European universities (Morais and Borrell-Damián 2019) or over $90 \%$ of Canadian institutions over 10 years ago (Greyson et al. 2009). However, IRs remain the officially endorsed channel for self-archiving while alternative means such as ASNs are not shunned. This survey reveals the pivotal role of the university library in campus scholarly publishing as it leads both in repository management and self-archiving of materials.

Our research shows a humble research incentivizing approach among UAE HEIs. As expected, most HEIs factor publishing records in promotion appraisals. The JIF remains the most tracked and valued metric despite being widely criticized as a research quality assessment tool (Moher et al.2018) and calls for recognizing the merits of the actual work and not the publication venue (Balez et al. 2019). However, the results also reveal that OA is not seen as a priority since most HEIs do not incentivize OA publishing, perceive OA publications neutrally during promotions, and offer no education on OA for researchers. 
This diverges from some institutions in North American and Europe reporting to have adopted tenure and promotion policies that factor OA publications in faculty appraisals (Odel et al. 2016; Morais and Barrell-Damián, 2019).

The survey results indicate that UAE HEIs do not appear to have mechanisms in place to deal with predatory journals. The majority are not aware of these journals, do not keep a list of potential predatory journals, and admit the challenge of identifying them. This is alarming since the UAE is one of the top ten countries claimed as the contact location on the predatory journals' websites according to Demir (2018). On the other hand, HEIs seem to put emphasis on journals being indexed in Scopus and WoS, albeit some of these may also be predatory journals that managed to get indexed in these services as demonstrated by Bagues, Sylos-Labini \& Zinovyeva (2019).

The level of awareness and adoption of OA among UAE HEIs suggests that if the UAE is to increase its presence in the OA movement, nation-wide strategies aligned with international initiatives such as OA2020 and Plan S need to be adopted. These strategies should translate into actionable policies and initiatives at the institutional and national level. We encourage replication of the survey in other parts of the world (provided as Appendix 1) in order to collectively collate a more nuanced representation of the true global stance towards OA. As OA seems to be the inevitable direction scholarly publishing at large is going there should be more knowledge concerning the current adoption, interest, and commitment to facilitate that change in various parts of the world.

We acknowledge a few limitations in our study. First, the survey return rate was less than $50 \%$, and not all respondents answered all survey questions. Second, a single survey does not generate longitudinal data which would provide a better measurement of the OA uptake. Finally, no distinction was made between scientific disciplines, and no comparison was made between institutions teaching in English and Arabic languages. Research on OA in the UAE is at its early stages, and further research is needed before we can fully understand the role that HEIs might play in improving the uptake of OA. Future studies on OA in the UAE may also investigate individual researchers' attitudes, experiences, and behaviors.

Acknowledgements The authors gratefully acknowledge the invaluable advice and input of Associate Prof. J. Tuomas Harviainen of Tampere University.

Open Access This article is licensed under a Creative Commons Attribution 4.0 International License, which permits use, sharing, adaptation, distribution and reproduction in any medium or format, as long as you give appropriate credit to the original author(s) and the source, provide a link to the Creative Commons licence, and indicate if changes were made. The images or other third party material in this article are included in the article's Creative Commons licence, unless indicated otherwise in a credit line to the material. If material is not included in the article's Creative Commons licence and your intended use is not permitted by statutory regulation or exceeds the permitted use, you will need to obtain permission directly from the copyright holder. To view a copy of this licence, visit http://creativecommons.org/licenses/by/4.0/.

\section{References}

Abritis, A., \& McCook, A. (2017). Cash incentives for papers go global. Science, 357(6351), 541-. https:// doi.org/10.1126/science.357.6351.541.

Al-Aufi, A. S. (2012). Domination of English and its impact on the Arabic System of Scholarly Communication. Journal of Arts and Social Sciences, 3(1), 5-28. https://doi.org/10.24200/jass.vol3iss1pp5-28.

Al Qasimi, B. (2017). UAE's publishing industry: A vision of an avant-garde nation. Publishing Research Quarterly, 33(1), 37-40. https://doi.org/10.1007/s12109-016-9494-z. 
Alperin, J. P., Muñoz Nieves, C., Schimanski, L., Fischman, G. E., Niles, M. T., \& McKiernan, E. C. (2018). How significant are the public dimensions of faculty work in review, promotion, and tenure documents? Humanities Commons [preprint]. https://doi.org/10.17613/M6W950N35.

AmeliCA. (2020). About AmeliCA. Retrieved from http://amelica.org/index.php/en/about.

Anderson, K. (2012). "Predatory" Open Access Publishers - The Natural Extreme of an Author-Pays Model. The Scholarly Kitchen. Retrieved from https://scholarlykitchen.sspnet.org/2012/03/06/predatory-openaccesspublishers-the-natural-extreme-of-an-author-pays-model/.

Austin, A. E., Chapman, D. W., Farah, S., Wilson, E., \& Ridge, N. (2014). Expatriate academic staff in the United Arab Emirates: The nature of their work experiences in higher education institutions. Higher Education, 68(4), 541-557. https://doi.org/10.1007/s10734-014-9727-z

Bagues, M., Sylos-Labini, M., \& Zinovyeva, N. (2019). A walk on the wild side: 'Predatory' journals and information asymmetries in scientific evaluations. Research Policy, 48(2), 462-477. https://doi. org/10.1016/j.respol.2018.04.013.

Bales, S., Hubbard, D. E., van Duinkerken, W., Sare, L., \& Olivarez, J. (2019). The use of departmental journal lists in promotion and tenure decisions at American research universities. The Journal of Academic Librarianship, 45(2), 153-161. https://doi.org/10.1016/j.acalib.2019.02.005.

Banks, D. (2018). Thoughts on publishing the research article over the centuries. Publications of the Astronomical Society of Australia, 6(1), 10. https://doi.org/10.3390/publications6010010.

Bauer, B., Gumpenberger, C., Haas, I., Katzmayr, M., Ramminger, E., \& Reinitzer, D. (2013). open access bestandsaufnahme an österreichischen universitäten: Ergebnisse einer umfrage im auftrag des forums universitätsbibliotheken österreichs (UBIFO). Mitteilungen der Vereinigung Österreichischer Bibliothekarinnen \& Bibliothekare, 66(3-4), 535-558.

Beall, J. (2012). Predatory publishers are corrupting open access. Nature, (489). Retrieved from https:// www.nature.com/polopoly_fs/1.11385!/menu/main/topColumns/topLeftColumn/pdf/489179a.pdf.

Beshyah, S. A., Hajjaji, I. M., \& Elbarsha, A. (2018). Awareness of predatory journals among physicians from Africa and the Middle East: An exploratory survey. Ibnosina Journal of Medicine and Biomedical Science. https://doi.org/10.4103/ijmbs.ijmbs_45_18.

Björk, B. C. (2017). Gold, green, and black open access. Learned Publishing, 30(2), 173-175. https://doi. org/10.1002/leap.1096.

Björk, B. C., Kanto-Karvonen, S., \& Harviainen, J. T. (2019). How frequently are articles in predatory open access journals cited. Publications, 8(2). https://doi.org/10.3390/publications8020017.

Björk, B. C., \& Solomon, D. (2014a). Developing an effective market for open access article processing charges. Final Report. https://doi.org/10.6084/m9.figshare.951966.

Björk, B. C., \& Solomon, D. (2014b). How research funders can finance APCs in full OA and hybrid journals. Learned Publishing, 27(2), 93-103. https://doi.org/10.1087/20140203.

Borrego, Á (2017). Institutional repositories versus ResearchGate: The depositing habits of Spanish researchers. Learned Publishing, 30(3), 185-192. https://doi.org/10.1002/leap.1099.

Boufarss, M. (2011). If we build it, will they come? A survey of attitudes toward institutional repositories among faculty at the Petroleum Institute. International Journal of Library Science, 3(1), 1-14.

Boufarss, M. (2020). Charting the Open Access scholarly journals landscape in the UAE. Scientometrics. https://doi.org/10.1007/s11192-020-03349-0.

Boufarss, M., \& Laakso, M. (2020). UAE HEIs open access institutional survey [Data set]. Zenodo. https:// doi.org/10.5281/zenodo.3831192.

Butler, L. (2003). Explaining Australia's increased share of ISI publications-the effects of a funding formula based on publication counts. Research Policy, 32(1), 143-155. https://doi.org/10.1016/s0048 -7333(02)00007-0.

Chapman, D., Austin, A., Farah, S., Wilson, E., \& Ridge, N. (2014). Academic staff in the UAE: Unsettled journey. Higher Education Policy, 27(1), 131-151. https://doi.org/10.1057/hep.2013.19.

Coalition, S. (2019). Plan S: Making full and immediate Open Access a reality. Retrieved from https://www. coalition-s.org.

Crawford, W. (2019a). Gold Open Access 2013-2018: Articles in journals (GOA4). Livermore, CA.: Cites \& Insights Books. Retrieved from https://waltcrawford.name/goa4.pdf.

Crawford, W. (2019b). Gold Open Access by Country 2013-2018. Livermore, CA.: Cites \& Insights Books. Retrieved from https://waltcrawford.name/goacntry4.pdf.

Creaser, C. (2010). Open Access to research outputs-Institutional policies and researchers' views: Results from two complementary surveys. New Review of Academic Librarianship, 16(1), 4-25. https://doi. org/10.1080/13614530903162854.

Demir, S. B. (2018). Predatory journals: Who publishes in them and why? Journal of Informetrics, 12(4), 1296-1311. https://doi.org/10.1016/j.joi.2018.10.008. 
Esposito, J. (2016). For Scholarly Communications, Double-dipping is Double the Fun. The Scholarly Kitchen. Retrieved from https://scholarlykitchen.sspnet.org/2016/08/01/for-scholarly-communicationsdouble-dipping-is-double-the-fun/.

European Commission Directorate-General for Research \& Innovation. (2017). H2020 programme guidelines to the rules on open access to scientific publications and open access to research data in horizon 2020. Retrieved from: https://ec.europa.eu/research/participants/data/ref/h2020/grants_manual/hi/ oa_pilot/h2020-hi-oa-pilot-guide_en.pdf.

Fernandez, L., \& Nariani, R. (2011). Open access funds: A Canadian library survey. The Canadian Journal of Library and Information Practice and Research. https://doi.org/10.21083/partnership.v6i1.1424.

Finnish National Board on Research Integrity TENK. (2019). The ethical principles of research with human participants and ethical review in the human sciences in Finland. Finnish National Board on Research Integrity TENK guidelines 3/2019. Retrieved from: https://www.tenk.fi/sites/tenk.fi/files/Ihmistiete iden_eettisen_ennakkoarvioinnin_ohje_2019.pdf.

Fitzgerald, B. F., \& Olwan, R. (2009) Copyright and innovation in the digital age: The United Arab Emirates. In E Commerce and Intellectual Property Conference, May 2009, UAE University, Abu Dhabi. https://eprints.qut.edu.au/21020/1/c21020.pdf.

Franzoni, C., Scellato, G., \& Stephan, P. (2011). Changing incentives to publish. Science, 333(6043), 702703. https://doi.org/10.1126/science.1197286.

Gdoura, W. (2009). Le Libre Accès dans les Universités Arabes: Opinions et Pratiques des Chercheurs et des Editeurs. In World Library and Information Congress: 75th IFLA General Conference and Council. Retrieved from https://www.ifla.org/past-wlic/2009/142-gdoura-fr.pdf.

GFH. (2016). GCC education: Sector report. Retrieved from https://www.gfh.com/wp-content/uploads/ GFH-Education-Sector-Report.pdf.

Gilbert, N. (2009). Editor will quit over hoax paper. Nature news. https://doi.org/10.1038/news.2009.571.

Greyson, D., Vézina, K., Morrison, H., Taylor, D., \& Black, C. (2009). University supports for open access: A Canadian National Survey. Canadian Journal of Higher Education, 39(3), 1-32..

Gulf News (2016). UAE initiatives a giant step to promote science. Retrieved from https://gulfnews.com/ opinion/editorials/uae-initiatives-a-giant-step-to-promote-science-1.1919870.

Gulf News (2017). UAE launches National Strategy for Higher Education 2030. Retrieved from https:// gulfnews.com/uae/education/uae-launches-national-strategy-for-higher-education-2030-1.2097191.

Harle, J. (2016). High prices to access scholarly research could drive developing country researchers to use pirate sites like SciHub. LSE: Impact Blog. Retrieved from http://blogs.lse.ac.uk/impactofsocialscienc es/2016/02/26/high-prices-scholarly-research-developing-country-researchers-scihub/.

Hicks, D. (2012). Performance-based university research funding systems. Research Policy, 41(2), 251-261. https://doi.org/10.1016/j.respol.2011.09.007.

Himmelstein, D. S., Romero, A. R., Levernier, J. G., Munro, T. A., McLaughlin, S. R., Tzovaras, G., B., \& Greene, C. S. (2018). Sci-Hub provides access to nearly all scholarly literature. ELife. https://doi. org/10.7554/eLife.32822.

Jamali, H. R. (2017). Copyright compliance and infringement in ResearchGate full-text journal articles. Scientometrics, 112(1), 241-254. https://doi.org/10.1007/s11192-017-2291-4.

Jisc. (2020). SHERPA/Juliet statistics. Retrieved from: https://v2.sherpa.ac.uk/view/funder_visualisations/1. html.

Johnson, R., Watkinson, A., \& Mabe, M. (2018). The STM Report: An overview of scientific and scholarly publishing, 5th Edition. https://www.stm-assoc.org/2018_10_04_STM_Report_2018.pdf.

Jolson, M. A. (1974). Criteria for promotion and tenure - A faculty view. Academy of Management Journal, 17(1), 149. https://doi.org/10.5465/254779.

King, D. W., \& Alvarado-Albertorio, F. M. (2008). Pricing and other means of charging for scholarly journals: a literature review and commentary. Learned Publishing, 21(4), 248-272. https://doi. org/10.1087/095315108X356680.

Kipphut-Smith, S., Boock, M., Chapman, K., \& Willi Hooper, M. (2018). Measuring Open Access Policy Compliance: Results of a Survey. Journal of Librarianship and Scholarly Communication, 6(1), eP2247. https://doi.org/10.7710/2162-3309.2247.

Kurmis, A. P. (2003). Understanding the limitations of the journal impact factor. The Journal of Bone and Joint Surgery. American Volume, 85(12), 2449-2454. https://doi.org/10.2106/00004623-20031200000028.

Laakso, M., Lindman, J., Shen, C., Nyman, L., \& Björk, B. C. (2017). Research output availability on academic social networks: implications for stakeholders in academic publishing. Electronic Markets. https ://doi.org/10.1007/s12525-016-0242-1. 
Laakso, M., \& Polonioli, A. (2018). Open access in ethics research: An analysis of open access availability and author self-archiving behaviour in light of journal copyright restrictions. Scientometrics, 116(1), 291-317. https://doi.org/10.1007/s11192-018-2751-5.

Lara, K. (2014). Open Access Library Survey. An investigation of the role of libraries in open access funding and support within institutions. Retrieved from http://www.pcgplus.com/wp-content/uploads/2014/09/ PCG-Open-Access-Library-Survey-2014.pdf.

Larivière, V., \& Sugimoto, C. R. (2018). Do authors comply when funders enforce open access to research? Nature news. https://doi.org/10.1038/d41586-018-07101-w.

Lovett, J. A., Rathemacher, A. J., Boukari, D., \& Lang, C. (2017). Institutional repositories and academic social networks: Competition or complement? A study of open access policy compliance vs. researchgate participation. Journal of Librarianship and Scholarly Communication, 5(1), eP2183. https://doi. org/10.7710/2162-3309.2183.

Mavodza, J. (2013). A review of the open access concept in the UAE. New Library World, 114(5/6), 259-266.

Max Planck Digital Library. (2020). OA2020: be informed. Retrieved from: https://oa2020.org/be-infor $\mathrm{med} /$.

Miller, J. C., Coble, K. H., \& Lusk, J. L. (2013). Evaluating top faculty researchers and the incentives that motivate them. Scientometrics, 97(3), 519-533. https://doi.org/10.1007/s11192-013-0987-7.

Mischo, W. H., \& Schlembach, M. C. (2011). Open access issues and engineering faculty attitudes and practices. Journal of Library Administration, 51(5-6), 432-454. https://doi.org/10.1080/01930 826.2011.589349.

Mitterlehner, B. (2013). Quality enhancement in tertiary education in the United Arab Emirates: An assessment of an international knowledge hub. Saarbrucken: Akademiker Verlag.

Moher, D., Naudet, F., Cristea, I. A., Miedema, F., Ioannidis, J. P. A., \& Goodman, S. N. (2018). Assessing scientists for hiring, promotion, and tenure. PLoS Biol, 16(3), e2004089. https://doi. org/10.1371/journal.pbio.2004089.

Morais, R., \& Borrell-Damián, L. (2018). Open access: 2016-2017 EUA survey results. Retrieved from https://www.eua.eu/resources/publications/324:open-access-in-european-universities-results-fromthe-2016-2017-eua-institutional-survey.html.

Morais, R., \& Borrell-Damián, L. (2019). Open access: 2017-2018 EUA survey results. Retrieved from https://www.eua.eu/downloads/publications/2017-2018\%20open\%20access\%20survey\%20results. pdf.

Mueller-Langer, F., Scheufen, M., \& Waelbroeck, P. (2020). Does online access promote research in developing countries? Empirical evidence from article-level data. Research Policy, 49(2), 103886. https://doi.org/10.1016/J.RESPOL.2019.103886.

Nasser, R., \& Abouchedid, K. (2001). Problems and the epistemology of electronic publishing in the Arab world: The case of Lebanon. First Monday, 6(9). https://doi.org/10.5210/fm.v6i9.886.

Odell, J., Coates, H., \& Palmer, K. (2016). Rewarding open access scholarship in promotion and tenure: driving institutional change. $C \& R L$ News, 77(7). Retrieved from https://crln.acrl.org/index.php/ crlnews/article/view/9518/10823.

Ofek, H. (2011). Why the Arabic World Turned Away from Science? The New Atlantis, (30), 3-23. Retrieved from https://www.thenewatlantis.com/publications/why-the-arabic-world-turned-awayfrom-science.

Piwowar, H., Priem, J., \& Orr, R. (2019). The Future of OA: A large scale analysis projecting Open Access publication and readership. BioRxiv, 795310. https://doi.org/10.1101/795310.

Pudovkin, A. I. (2018). Comments on the Use of the Journal Impact Factor for Assessing the Research Contributions of Individual Authors. Frontiers in Research Metrics and Analytics, 3(2). https://doi. org/10.3389/frma.2018.00002.

QS Quacquarelli Symonds Limited. (2019). World University Rankings, Q. S. QS 2020. Retrieved from https://www.topuniversities.com/university-rankings/world-university-rankings/2020.

Quan, W., Chen, B., \& Shu, F. (2017). Publish or impoverish: An investigation of the monetary reward system of science in China (1999-2016). Aslib Journal of Information Management, 69(5), 486502. https://doi.org/10.1108/AJIM-01-2017-0014.

ROARMAP. (2020). Data visualisations. Retrieved from: http://roarmap.eprints.org/dataviz2.html.

Rumsey, S. (2017). OA in the UK: State of the Nation. International Journal of Legal Information, 45(1), 56-61. https://doi.org/10.1017/jli.2017.15.

Ryan, J. (2017). Unleash power of scientific research to stimulate the UAE knowledge economy. The National. Retrieved from https://www.thenational.ae/business/unleash-power-of-scientific-resea rch-to-stimulate-the-uae-knowledge-economy-1.68716. 
Ryan, J. C., \& Daly, T. M. (2018). Barriers to innovation and knowledge generation: The challenges of conducting business and social research in an emerging country context. Journal of Innovation \& Knowledge, 4(1), 47-54. https://doi.org/10.1016/j.jik.2017.10.004.

Sajjad Ahmed, S., \& Al-Baridi, S. (2012). An overview of institutional repository developments in the Arabian Gulf Region. OCLC Systems \& Services: International Digital Library Perspectives, 28(2), 79-89. https://doi.org/10.1108/10650751211236613.

Sanderson, D., \& Khan, S. (2019). Ghadan 21: Abu Dhabi to boost business and ecotourism with major new reforms. The National. Retrieved from https:/www.thenational.ae/uae/government/ghadan-21abu-dhabi-to-boost-business-and-ecotourism-with-major-new-reforms-1.878805\#14.

SCImago. (2019). SJR - SCImago Journal \& Country Rank. Retrieved from https://www.scimagojr.com/ countrysearch.php?country=ae.

Shah, T. A., \& Gul, S. (2013). Philosophy of escapism in the open access world: Studying author pay model. Library Review, 62(4/5). https://doi.org/10.1108/LR-09-2012-0104.

Shawabka, Y. A., \& Bouazza, A. S. (2007). Trends of Faculty at the UAE University towards the Open Access System of Scientific Information, The Eighteenth Conference of the Arab Federation for Libraries and Information (AFLI), Jeddah 17-20 November 2007. (in Arabic).

Shen, C., \& Björk, B. C. (2015). Predatory" open access: A longitudinal study of article volumes and market characteristics. BMC Medicine, 13(1), 230-245. https://doi.org/10.1186/s12916-015-0469-2.

SPARC. (2019). Big Deal Cancellation Tracking. Retrieved from https://sparcopen.org/our-work/big-dealcancellation-tracking/.

Spender, T., \& Bardsley, D. (2009). University study faults lack of tenure. The National. Retrieved from https://www.thenational.ae/uae/education/university-study-faults-lack-of-tenure-1.489374.

Springer, \& Nature, (2018). Nature index: 2018 tables. Retrieved from https://www.natureindex.com/annua 1 -tables/2018.

Taha, A. (2007). Networked e-information services to support the e-learning process at UAE University. The Electronic Library, 25(3), 349-362. https://doi.org/10.1108/02640470710754850.

Tennant, J. P., François, W., Jacques, D. C., Paola, M., Collister, L. B., \& Chris, H.. H. J. (2016). The academic, economic and societal impacts of open access: An evidence-based review. F1000Research, 5. https://doi.org/10.12688/f1000research.8460.1.

Tenopir, C., Dalton, E., Christian, L., Jones, M., McCabe, M., Smith, M., \& Fish, A. (2017). Imagining a gold open access future: attitudes, behaviors, and funding scenarios among authors of academic scholarship. College \& Research Libraries, 78(6). https://doi.org/10.5860/crl.78.6.824.

Times Higher Education. (2019). Emerging Economies University Rankings 2019. Retrieved from https ://www.timeshighereducation.com/world-university-rankings/2019/emerging-economies-university -rankings\#!/page/0/length/25/sort_by/rank/sort_order/asc/cols/stats.

UAE PMO. (2014). UAE vision 2021. Retrieved from https://www.vision2021.ae/en.

UAE PMO. (2015). UAE national innovation strategy. Retrieved from https:/www.moei.gov.ae/assets/ download/1d2d6460/National\%20Innovation\%20Strategy.pdf.aspx.

UAE PMO. (2019). Share of the UAE nationals in the workforce. Retrieved from https://www.vision2021 .ae/en/national-agenda-2021/list/card/share-of-uae-nationals-in-the-workforce.

United Nations Development Programme and Mohammed bin Rashid Al Maktoum Knowledge Foundation, (2016). Arab Knowledge Index 2016. Retrieved from http://knowledge4all.com/AKDataVisualizationI ndex.aspx ?language $=$ en $\&$ year $=2016 \#$ StartPage.

United Nations Development Programme and Mohammed bin Rashid Al Maktoum Knowledge Foundation, (2018). Global Knowledge Index 2018: data visualization. Retrieved from http://knowledge4all.com/ en/DataVisualization.

Vanclay, J. K. (2009). Bias in the journal impact factor. Scientometrics, 78(1), 3-12. https://doi.org/10.1007/ s11192-008-1778-4.

Van Weijen, D. (2012). The language of (future) scientific communication. Research Trends, 31, 7-8. 